\title{
The Role of Teachers' Digital Communication Skills in the Success of the Distance Learning Process in Private Universities in Lebanon
}

\author{
Violla Makhzoum ${ }^{1}$, Amine Berri ${ }^{2}$, Zeinab Ajami \\ ${ }^{1}$ Islamic University of Lebanon, Lebanon. Email: violla.makhzoum@iul.edu.lb \\ ${ }^{2}$ Jinan University, China. Email:aminberri112@gmail.com \\ ${ }^{3}$ Saint Joseph University, Lebanon. Email: zeinabajami@hotmsil.com
}

\begin{tabular}{|c|c|}
\hline Article Info & Abstract \\
\hline $\begin{array}{l}\text { Article history: } \\
\text { Received: } 15 \text { October } 2020 \\
\text { Revised: } 25 \text { January } 2021 \\
\text { Accepted: } 28 \text { January } 2021\end{array}$ & $\begin{array}{l}\text { Purpose: This research study aims to examine the role of effective digital } \\
\text { communication skills in the success of the distance learning process in the } \\
\text { private universities in Lebanon. It also addresses the role of the teacher in } \\
\text { motivating the students and acting as a facilitator to bridge the digital } \\
\text { divide. }\end{array}$ \\
\hline $\begin{array}{l}\text { Keywords: } \\
\text { Distance Learning, } \\
\text { Effective Communication } \\
\text { Skill, } \\
\text { Twenty-First Century Skills, } \\
\text { Motivation, } \\
\text { Digital Divide. }\end{array}$ & $\begin{array}{l}\text { Approach/Methodology/Design: To achieve the goal of this research, a } \\
\text { descriptive approach was adopted. Six private universities were selected as } \\
\text { a sample for the study and they were selected randomly. A questionnaire } \\
\text { was developed as a tool for data collection. To verify the validity and } \\
\text { reliability of the questionnaire, we used the Cronbach coefficient test } \\
\text { (Cronbach's alpha). The researchers distributed } 300 \text { questionnaires to } \\
\text { respondents from the selected private universities. Only } 137 \text { teachers } \\
\text { responded, or }(45.6 \%) \text { of the total questionnaires distributed. For statistical } \\
\text { analysis, the researchers used SPSS version } 20.0 \text {. }\end{array}$ \\
\hline Paper Type : & $\begin{array}{l}\text { Findings: The results of the study revealed that private universities in } \\
\text { Lebanon were ready to handle online teaching during the CoViD-19 }\end{array}$ \\
\hline Research Article & $\begin{array}{l}\text { pandemic. The respondents indicated their ability to handle the newly- } \\
\text { emerging digital technologies to tackle crisis. It is found out that the }\end{array}$ \\
\hline Corresponding Author: & $\begin{array}{l}\text { arithmetic average rate related to the extent of the role that the teacher } \\
\text { plays in the success of the distance learning process is }(3.80) \text { with a }\end{array}$ \\
\hline Violla Makhzoum & $\begin{array}{l}\text { "strong" degree. The arithmetic average rate of the teacher's possession of } \\
\text { the skill of effective communication was (3.69), with a "strong" degree. As }\end{array}$ \\
\hline $\begin{array}{l}\text { Email: } \\
\text { violla.makhzoum@iul.edu.lb }\end{array}$ & $\begin{array}{l}\text { for the teacher's role in the process of motivation, the average of the } \\
\text { arithmetic mean was } 3.59 \text { with a "strong" degree, but it is closer to an } \\
\text { "average" than to a "strong" degree. }\end{array}$ \\
\hline & $\begin{array}{l}\text { Practical Implications: The study presents various implications for different } \\
\text { stakeholders; it principally addresses a crucial recent issue, and thus serves } \\
\text { as a source for teachers and administrators. The results of the study open } \\
\text { new venues for further research on online learning. } \\
\text { Originality/value: The success of online learning is dependent on digital } \\
\text { literacy. The familiarity with the new technological means that emerged } \\
\text { during } 2020 \text { contributes to the success }\end{array}$ \\
\hline
\end{tabular}

\section{Introduction}

Charles Horton Cooley (1929) defines communication as the mechanism through which human relations exist and develop all the symbols of the mind, together with the means of conveying them through space and preserving them in time. It includes the expression of the 
face, attitude and gesture, the tones of the voice, words, writing, printing, railways, telegraphs, telephones, and whatever else may be the latest achievement in the conquest of space and time (Stanek et al., 2014). Based on this definition, it is realized that communication has two basic functions: The first function is cognitive, working to transmit and communicate mental symbolism, while the second function plays an important role in strengthening and activating human relations at the verbal and non-verbal level (Lemonier, 2016). Through this process, correspondents and recipients of messages interact in specific social contexts (Hege et al., 2020).

With the spread of the corona virus across the world and becoming a dangerous pandemic threatening humanity, most of the countries enforced a complete shutdown in line with the recommendations of the World Health Organization (WHO, 2020). This led to the shutdown of most of the vital sectors, especially the educational one, to protect students' and teachers' lives. Such a situation compelled the authorities of the educational sector in many countries to find alternative methods to continue the educational process. The distance learning process was the suitable method, as it depends on the existence of spatial boundaries that separate the teacher from the student (Ilmiyah \& Setiawan, 2020). It also depends on multiple communication modes to be successful. Modern means of communication have contributed to creating new educational methods that serve the educational system and address its economic and social issues (Clark, 2020). This process also requires additional effort from both teachers and students, especially in terms of inter-communication. The educational stages and age groups impose means and methods that are specific to each stage and category to make this process successful.

Education is unfortunately the last thing that governments consider in times of crises and pandemics( Alharbi, 2020). In such unexpected situations, the teacher like everyone else suffers from the psychological pressure that he/she and his/her family are experiencing in the wake of the corona virus economic crisis. Teachers have to make a huge efforts to adapt to the emerging distance learning process and sometimes come across students who are not interested in the 'learning through a screen' method. The emerging new teaching/learning environment imposed challenges and forced teachers to innovate and even familiarize themselves with new digital skills. In addition, students particularly in third world countries were not able to accommodate the new educational changes. Mukhtar et al. (2020) indicated that students were reluctant to accept the new changes in their learning environments. Their sense of apprehension is reflected in their seriousness towards the subjects being taught. Online for them was merely for fun because they thinks that lectures will be explained later after they return to their universities. Therefore, the students find learning teaching/learning online to be boring and of little benefit, and this is where the problem of this research study lies.

The research study addresses how important it is for the teacher to have the needed digital communication skills, and the role that these skills play in conveying knowledge to students and exchanging it. In addition, the study explore how teachers can innovate in their teaching and motivate the students to the academic year successful, especially that we are going 
through this experience for the first time in Lebanon and in most Arab countries. The teacher has to be innovative and also he has to play an active role in motivating the students. The guiding question in this study is whether the teacher's method in the distance learning process plays an effective role in making this process successful. There are also more specific questions focusing more on whether possessing "digital" communication skills contribute to the success of the distance learning process, and whether teachers play a role in motivating the student through the distance learning process.

\section{Literature Review}

Many studies have tackled the role that effective communication plays in the success of the distance learning process, but what this study adds is the role of effective communication in stimulating the student morally, in addition to supporting them to overcome the difficult times that the country is going through during the Corona pandemic. The study by Subotzky and Primsloo (2011) stated that effective communication contributes to enhancing the student's senses in line with active listening skills, the ability to adapt the communication method with others, and enhancing self-confidence. In addition to receiving feedback and clarity, choosing the right voice tone, having sympathy and respect for others. All this contributes to the development of the student's abilities to analyze and communicate effectively during the distance learning process.

In their study, Simomson et al. (2019) concluded that effective communication ultimately leads to the sharing and exchanging of information between the concerned parties in a smooth and clear manner. The concept of effective communication is widely used in the organization sector to enhance the mechanisms of cooperation, participation and implementation of tasks as required per each organization. Therefore, effective communication skills must be used to ensure successful communication.

Murillo-Zamorano \& All (2019) pointed out that despite the existence of the effective communication skills; there is a set of obstacles that prevent interpersonal communication from being positive. Among the main obstacles that they identified are acoustic obstacles, health obstacles, linguistic obstacles, and cultural barriers. Acoustic obstacles are associated with the presence of noise in the communication environment, increasing the difficulty of communicating with them (Murillo-Zamorano \& All, 2019). The health obstacles are in the form of diseases, such as hearing impairment or blindness. In terms of linguistics, the presence of a language barrier, whether at multilingualism level or at the misuse of language level, due to grammatical or linguistic errors can be an obstacle. Cultural barriers exist as certain assumptions on each aspect of communication, which are based on different cultural backgrounds (Murillo-Zamorano \& All, 2019). More importantly, the issue of digital divide can be a barrier today. With the increasing pressure to employ advanced technological tools in teaching, old generation teachers may find it difficult to teach online. This poses a considerable challenge to educational institutions. 
Hodges \& Al (2020) concluded that the communication process is considered a "link" between people, because this process is a social activity in which people interact with each other. Therefore, any activity must have a set of rules that govern it in terms of elements and obstacles. The importance of communication also lies in the fact that it is a process that strengthens peoples' cultures, as this skill contributes to life advancement and continuation. This study also aims at extending a bridge of cooperation and bridging the gap between communication concepts, identifying means of communication, their obstacles, and effective communication strategies. In addition, it introduces the word 'digital' in order to emphasize the communication through new technological means.

\section{Methodology and Procedures}

In this research, we relied on the descriptive method. We began by describing the phenomenon we are studying, gathering accurate information about it, and describing it in quantitative and qualitative manner. Then we proceeded to analyse the phenomenon and explain the reasons that may lay behind the problems (Elliott \&Timulak, 2005). The type of sampling technique that was used in this research is simple random sampling. This means that all members of the research community have an equal and independent opportunity to enter the sample, signifying that every individual in the community has the same possibility of selection, and choosing any individual does not affect choosing the other (long \& All, 2016). We used a questionnaire as our tool for data collection. To verify the validity and reliability of this questionnaire, we used the Cronbach coefficient test (Cronbach's alpha). This test indicates the accuracy of measuring the test items for the target sample, in addition to the low percentage of random errors of measurement affecting the accuracy of test scores, according to Lane et al., (Lane et al., 2017, p. 226). Table No. 1 shows the value of the Cronbach alpha test.

Table No. (1): Reliability Test

\begin{tabular}{|c|c|}
\hline Number of items & Reliability analysis \\
\hline 60 & 0.84 \\
\hline
\end{tabular}

Therefore, the minimum test for the Cronbach's Alpha coefficient should be higher than (0.65) to confirm the reliability of the results, according to Goforth (2015). If the Cronbach's Alpha scale does not reach (0.60), then this should be a warning alert, also according to Dornyei (2007). It is clear from the above table that the value of Cronbach's Alpha coefficient is equal to $(0.84)$, which is greater than $(0.65)$.

\section{Study Boundaries:}

- Objective boundaries are determined in studying the role that effective communication skills play in the success of the distance learning process.

- Spatial boundaries: This study was applied to a sample of private universities in Lebanon. Six private universities were selected.

- Temporal boundaries: This study was applied in the spring and summer semesters 
of the academic year 2019/2020.

\section{Distributing the study tool (questionnaire) to teachers:}

The questionnaires were distributed to teachers in the private universities, which were included in the sample, according to Chart No. (1), as follows:

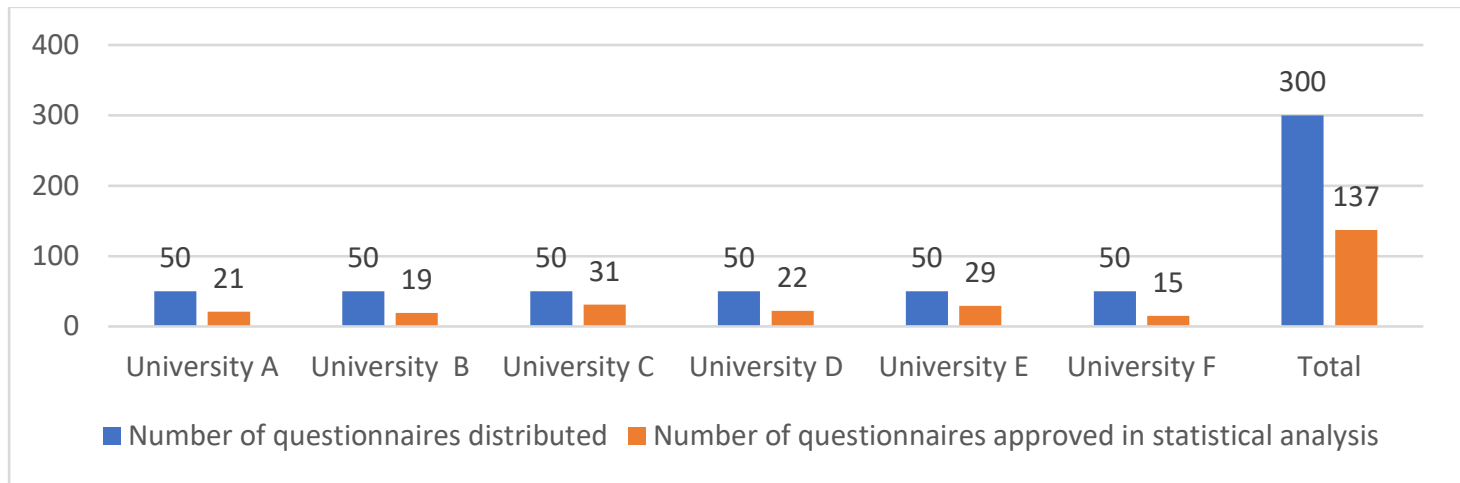

Graph No. (1): the number of questionnaires distributed to teachers

As shown in Graph No. (1), the researchers distributed 300 questionnaires to the private universities that were included in the sample, but only 137 teachers responded, or $(45.6 \%)$ of the total questionnaires distributed. Questionnaires were distributed by email. For statistical analysis, the researchers used SPSS version 20.0.

\section{Results and Discussion}

\section{Demographic Results:}

In this section, a set of characteristics of the individuals in the sample are identified. Starting with the quantitative characteristics that include the gender and age of the teachers included in the sample. In addition to the qualitative characteristics, which include social factors such as teachers' academic specialization and their years of work in the universities, was conducted (Staveteig, 2016). The demographic results were as follows:

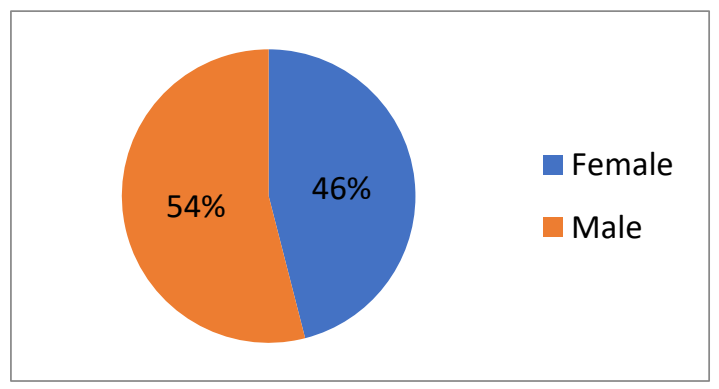

Graph No. (2): the distribution of teachers according to the gender variable

For those who were included in the sample, we found that the number of male teachers $(57 \%)$ exceeded the number of female teachers $(43 \%)$. 


\section{Distribution of teachers according to the age variable:}

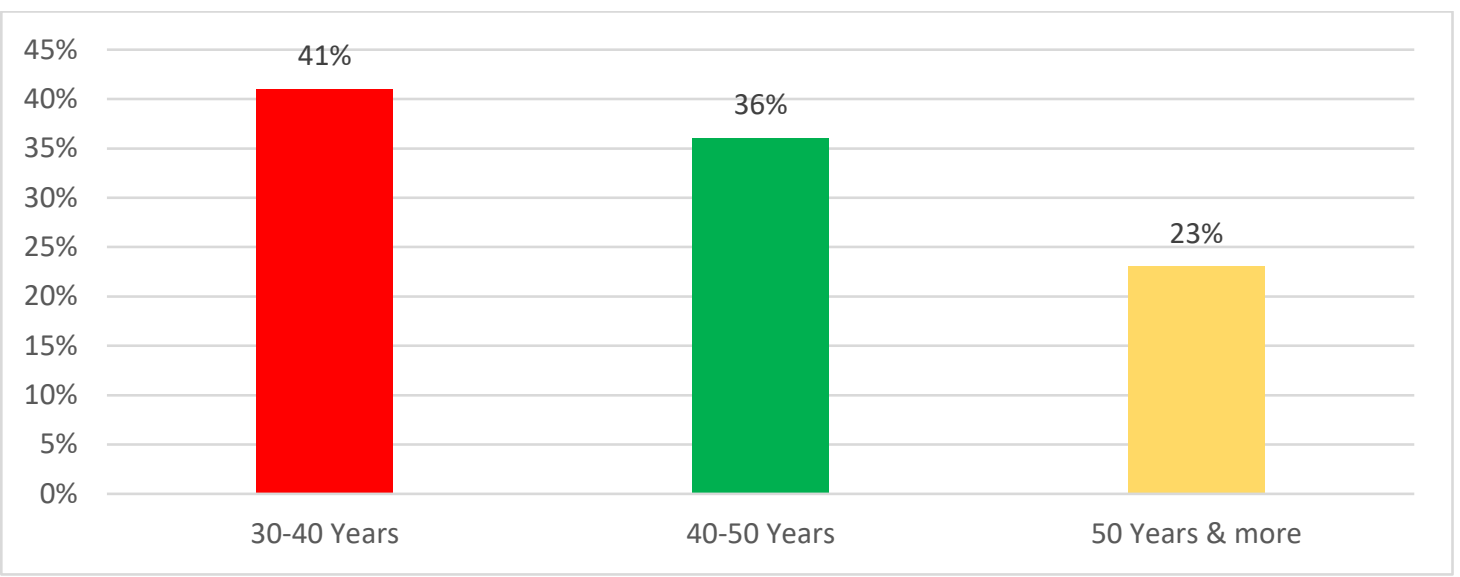

Graph No. (3): the distribution of teachers according to the age variable

Teachers whose ages ranged between (30-40 years) at (41\%) set the highest participation rate, they were followed by teachers whose ages ranged between (40-50 years) with (36\%), and finally teachers whose age reached (50 years and above) - by (23\%).

\section{Distribution of teachers according to the variable of Academic Specialization:}

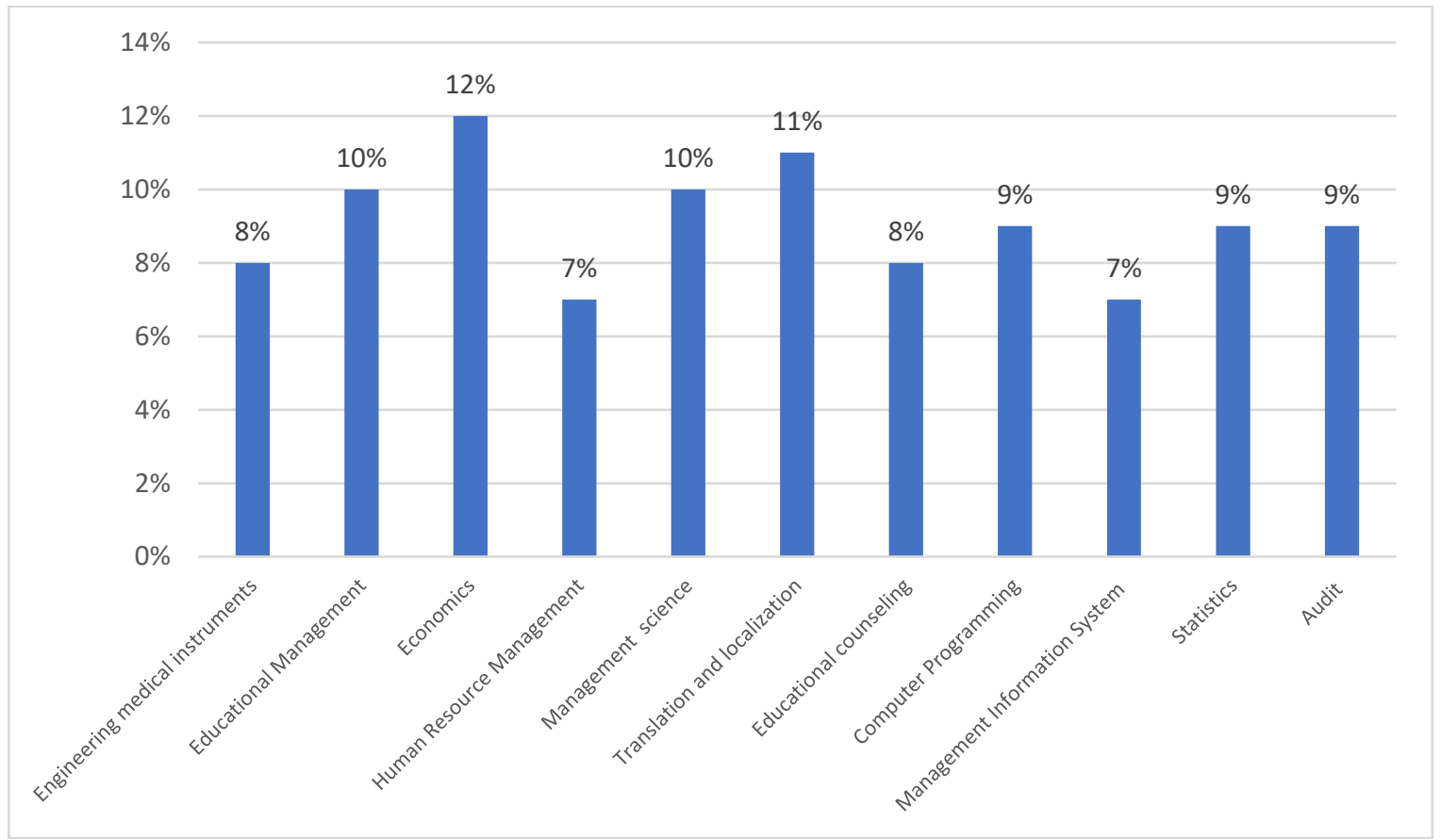

Graph No. (4): the distribution of teachers according to the variable of Academic Specialization

The results presented in the above graph shows that the highest participation rate is set by teachers specialized in economics at (12\%), while the lowest participation rate was set by teachers specialized in human resources management and information systems management at $(7 \%)$. 
Distribution of teachers according to the academic degree variable:

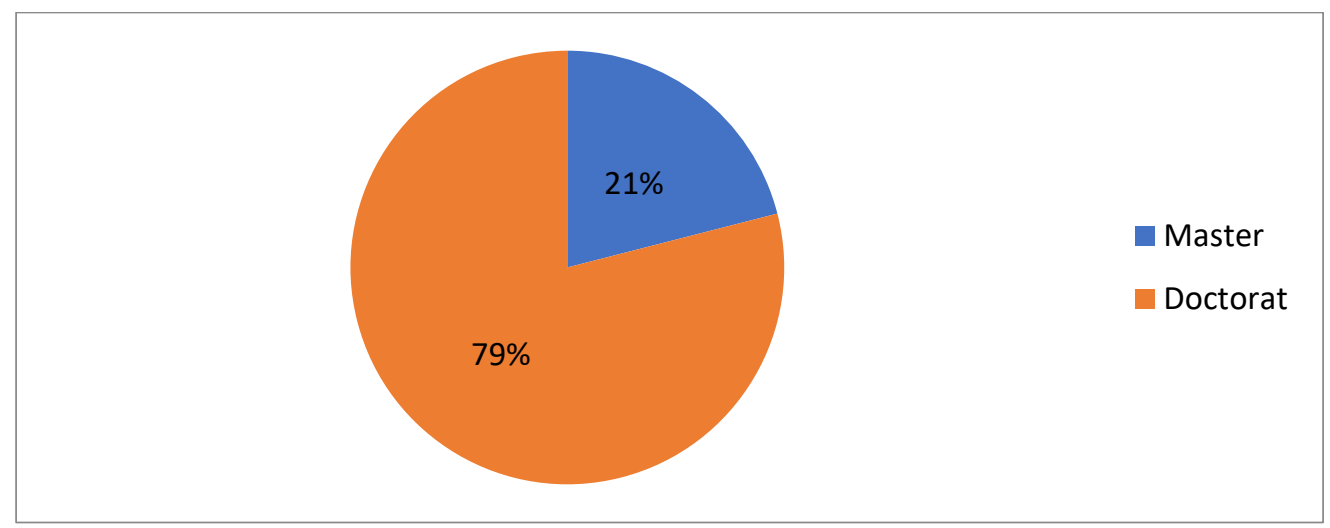

Chart No. (5): the distribution of teachers according to the academic degree variable

Graph No. (5) shows that the teachers who were included in the sample were distributed as follows: $(21 \%)$ of them were master's degree holders and $(79 \%)$ of them were doctorate degree holders.

\section{Distribution of teachers according to the variable of practical experience:}

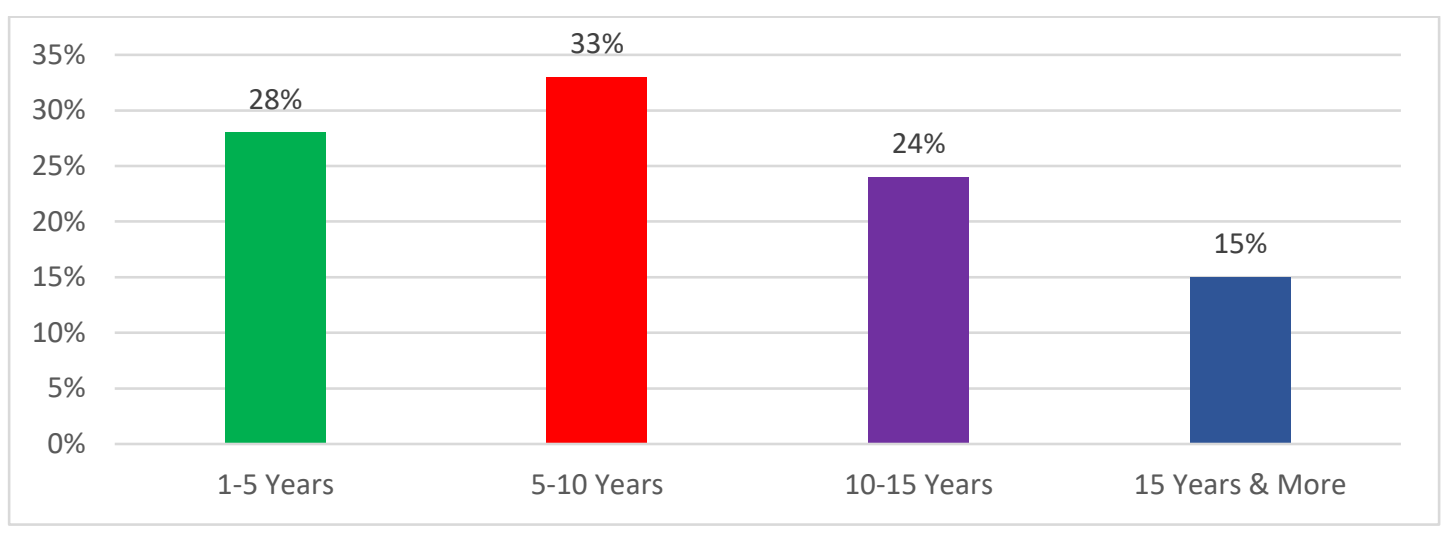

Graph No. (6): the distribution of teachers according to the variable of practical experience

Through the above graph, the experience of the teachers who participated in this study was distributed among four groups. The percentage of teachers who have practical experience between (5-10 years) reached (33\%), while the percentage of those who have practical experience between (1-5 years) reached (28\%), followed by those whose practical experience ranged between (10-15 years) by (24\%), and the fourth and final category by (15\%) for those with experience of 15 years and above.

\section{Answers to the research questions:}

In this section, the responses to the research questions are presented. The first research question: 
- Does the teacher's method in the distance learning process play an effective role in making this process successful?

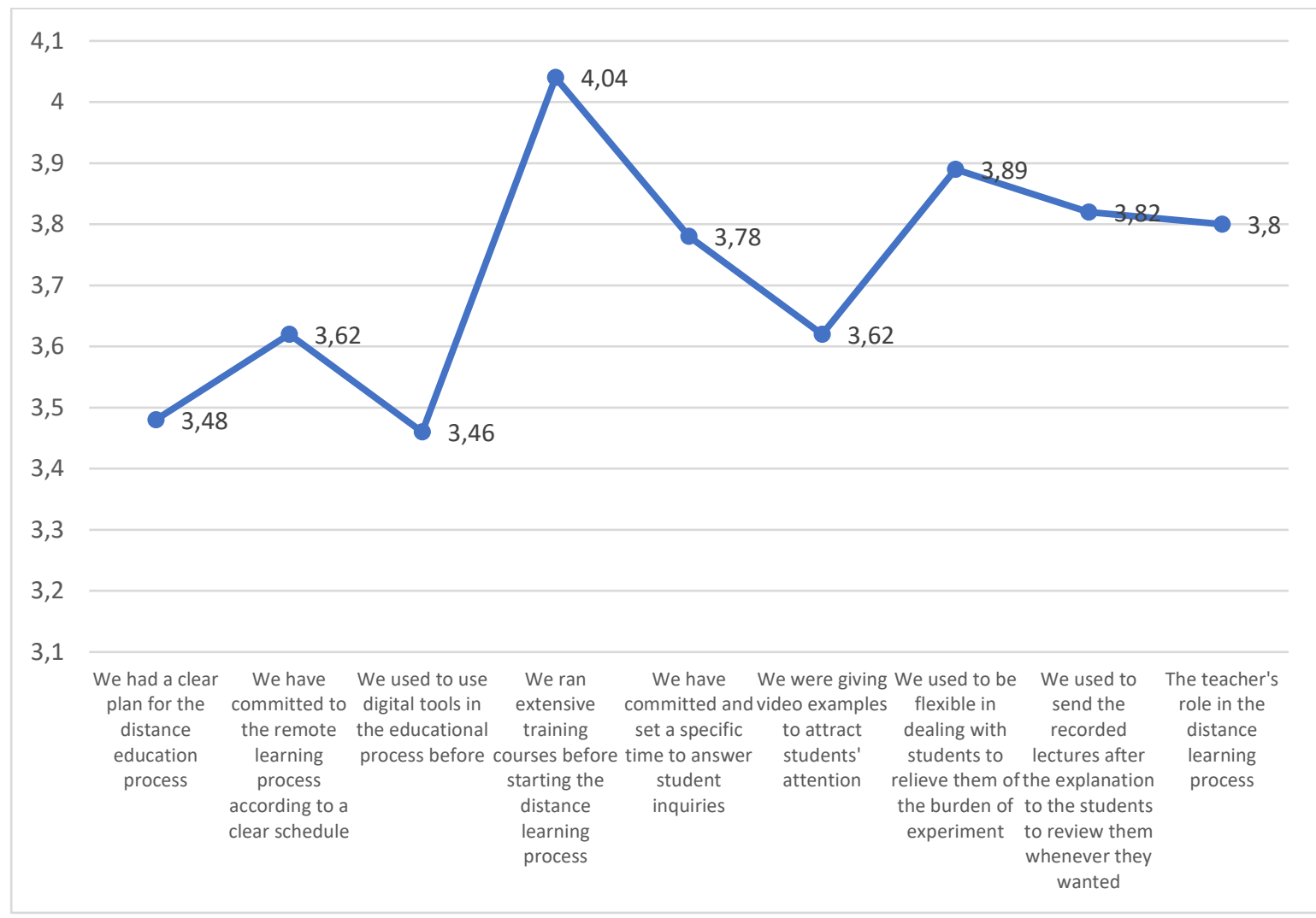

Graph No. (7): Distribution of teachers 'answers on the field related to the teacher's method in making the process of distance learning successful

Through the above graph, we found that the general arithmetic mean reached (3.80) with a strong degree, and this means that most of the teachers who were included in the sample had a clear plan to conduct the distance learning process and to give sufficient time to students. The highest arithmetic mean of the teachers' response (4.04) was strongly reported to the statement: "we have implemented intensive training courses before starting the distance learning process". This indicates the readiness of universities to face crises and their ability to acquire the digital technologies they need to face each crisis. While the lowest arithmetic mean scored (3.46) with an average degree on the statement: "We have previously used digital means in the educational process" and this may indicate the nature of the courses taught by the teacher or the universities' financial ability to purchase these digital technologies. It may also refer to the study plan adopted by the university and its seriousness in keeping pace with the developments imposed by the twenty-first century. The second research question: Does the teachers' possession of the skill of effective communication contribute to the success of the distance learning process? 


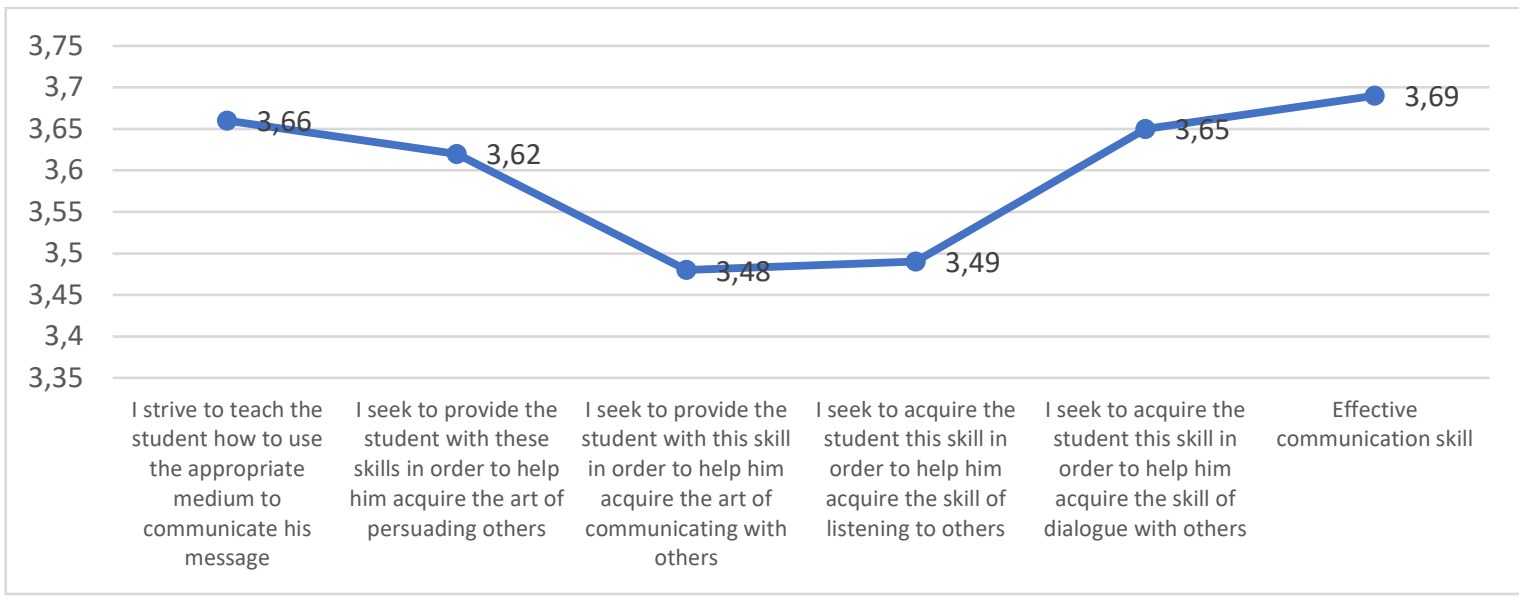

Graph No. (8): the distribution of teachers 'responses on the field related to teachers' possession of the skill of effective communication

Through the above graph, we have found that the general arithmetic mean reached (3.69) with a strong degree. This means that most of the teachers included in the sample possess the skill of effective communication to a good degree. The importance of this skill lays in its representation of the capabilities we use when presenting or receiving various types of information, such as conveying ideas and feelings to others. The highest general arithmetic mean was (3.66) with a (strong) degree in the teachers 'answers, most of which reached (I agree) to the statement: "I use the appropriate mean to deliver the message to the student according to its goal". Meanwhile, the minimum arithmetic mean reached (3.48) with a (medium) degree in the answers of most teachers to the phrase "I communicate with the student orally and in writing in a clear and expressive manner" and to the statement "I seek to make the student gain this skill in order to help him/her acquire the art of communicating with others".

The third research question: Does the teacher play a role in motivating the student during the distance learning process?

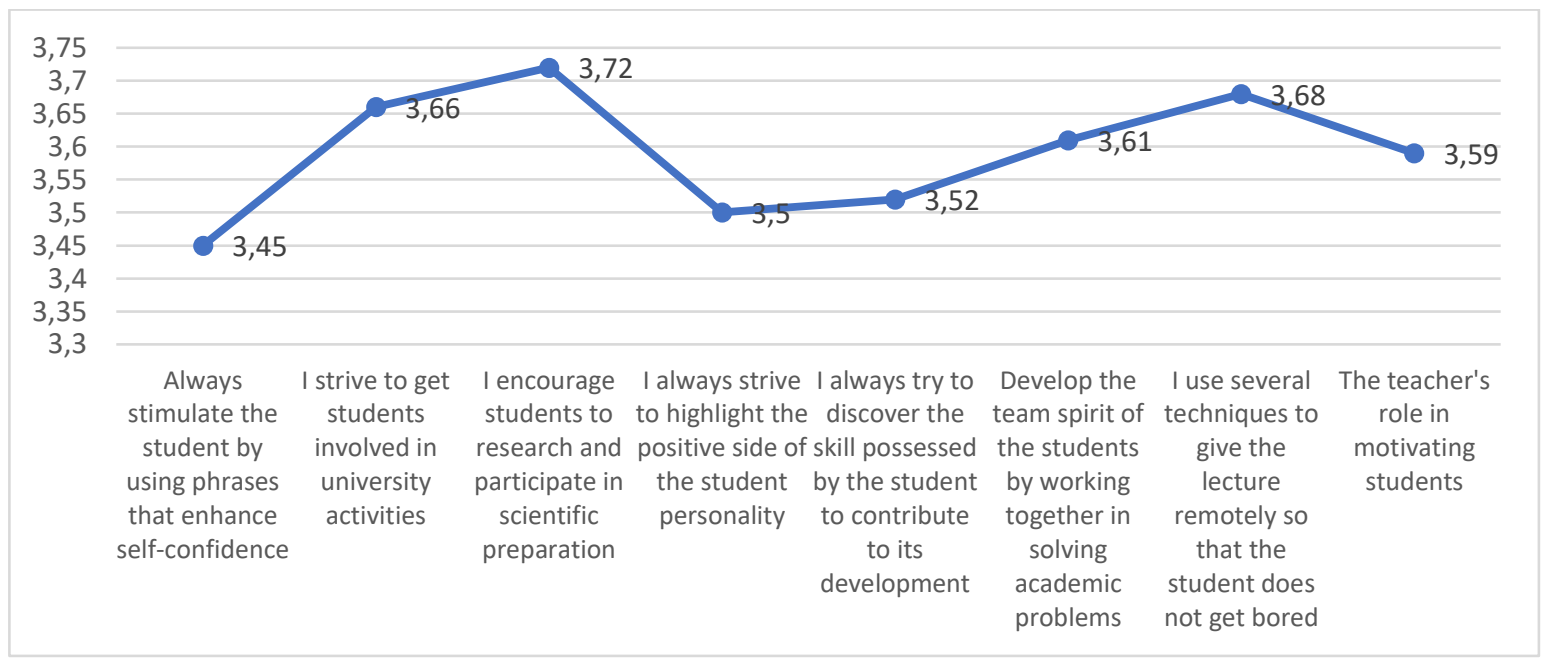

Graph No. (9) Distribution of teachers 'answers on the field related to the teacher's role in motivating the student 
Through the above graph, we have found that the general arithmetic mean reached (3.59) with a (strong) degree, but it is closer to the (average) degree than to the (strong) degree. This means that most of the teachers who were included in the sample possess the skill of motivation, but the value of the arithmetic mean indicates that universities should organize intensive training courses for teachers to improve the role they play in motivating the students. The highest general arithmetic mean was (3.72) with a (strong) degree in the teachers 'answers, most of which reached (I agree) to the following statement: "I encourage students to research and participate in scientific preparation". As for the minimum arithmetic mean, it reached (3.45) with a (weak) degree in most teachers' answers to the statement "Always stimulate the student by using phrases that enhance self-confidence."

Comparing demographic results with developing the twenty-first century skills of teachers in the private universities that were included in the sample:

Comparing the arithmetic means for each field according to the gender variable:

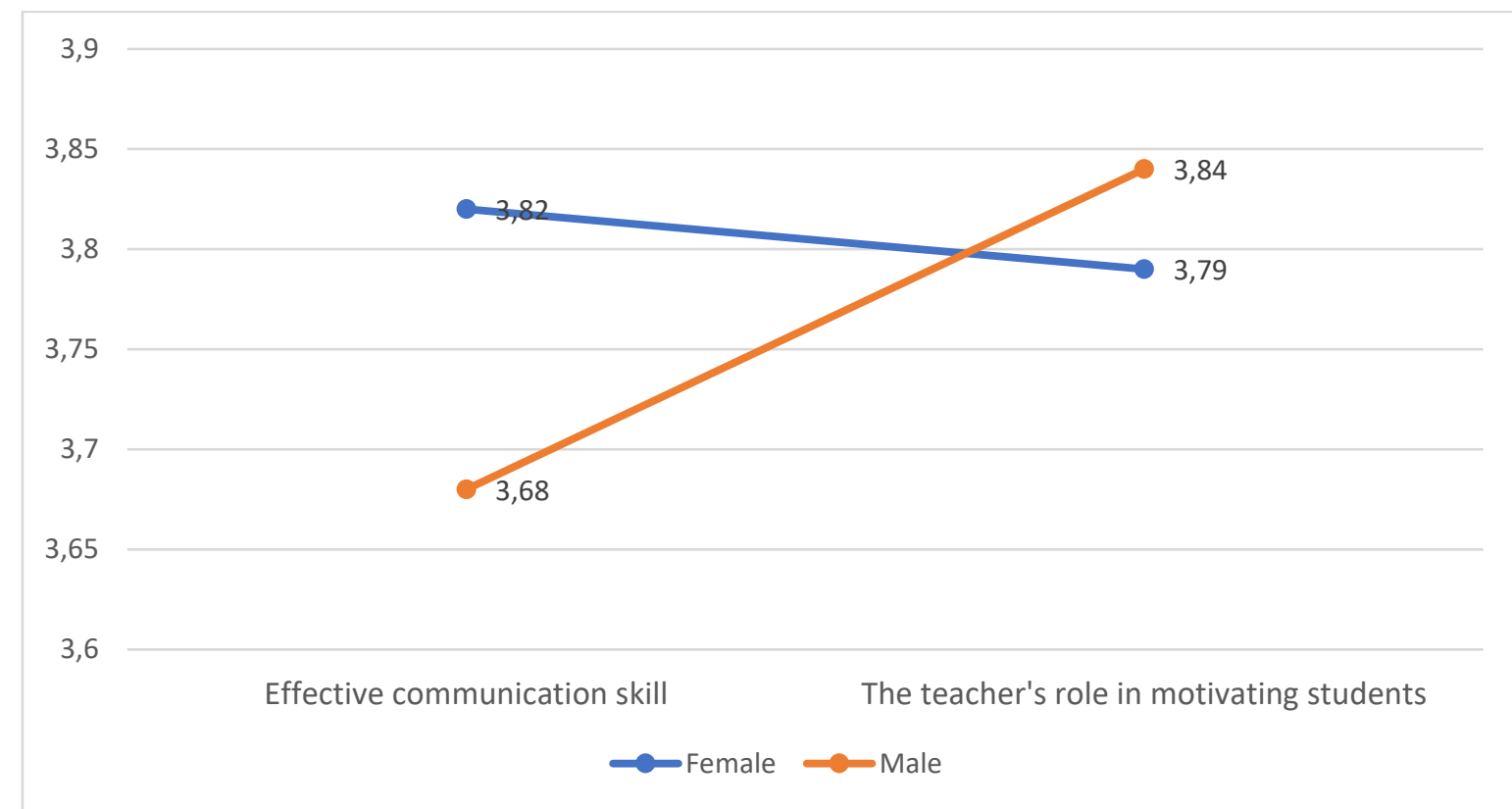

Graph No. (10): a comparison between the arithmetic averages for each field according to the gender variable

Through the above graph, we have found that female teachers possess the skill of effective communication at a rate (3.82) higher than that of male teachers, which reached (3.68). Regarding student motivation, we found that male teachers possess this skill at a rate (3.84) higher than the rate of female teachers (3.79). Based on the importance of these two great skills in the success of the distance learning process, it is of high importance for both female and male teachers to master these two skills. Therefore, universities must work to develop these two skills among their teachers to be able to withstand and face this new challenge that was imposed on them without any warning. 


\section{Comparing the arithmetic averages for each field according to the age variable:}

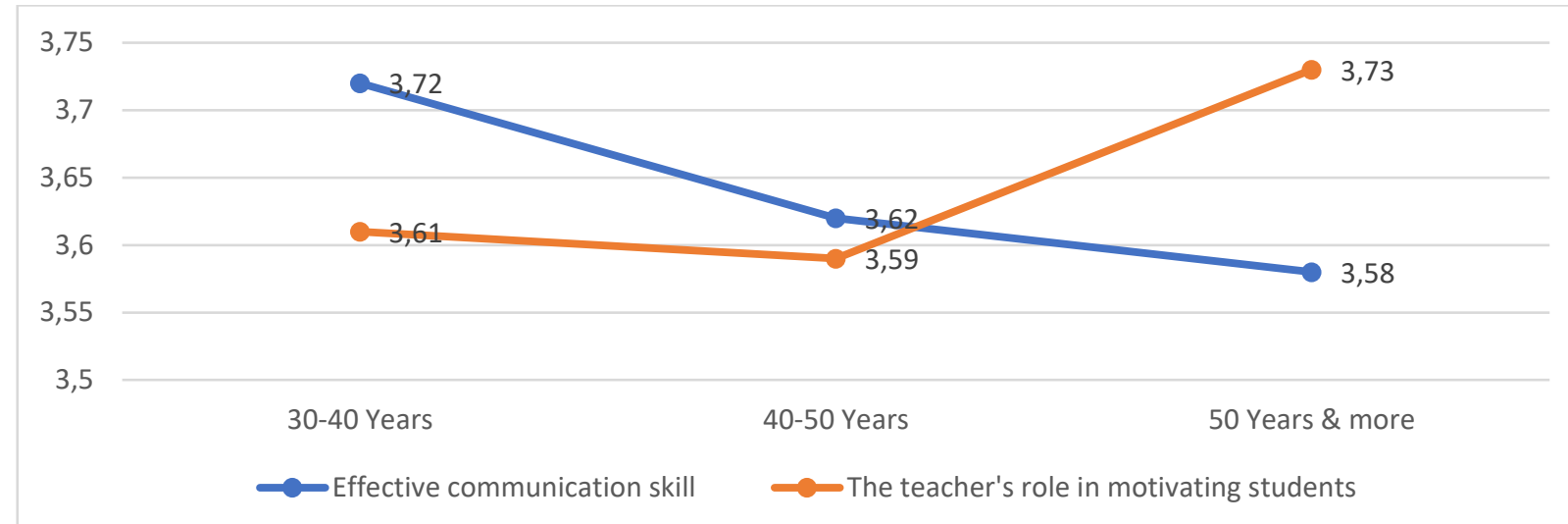

Graph No. (11): a comparison between the arithmetic mean for each field according to the age variable

Based on statistical analysis and by comparing the arithmetic means for each field according to the age variable of the teachers who were included in the sample, we found that teachers whose ages ranged between (30-40years) recorded the highest arithmetic mean (3.72) in possessing the skill of effective communication. We also found that teachers whose ages ranged between (40-50) scored the highest arithmetic mean (3.62) in possessing the skill of communication as well, while teachers whose ages ranged between (50 years and above) possessed the skill of motivating students with an average of (3.73).

Based on these results, universities should set up an annually or quarterly evaluation system for teachers, which can reveal the skills that teachers need to develop and work on developing them to serve the study plans and programs that universities seek to achieve. This is crucial since keeping up with all the rapid changes and developments of the twenty-first century demand us to work tirelessly and continuously.

\section{Comparing the arithmetic means for each field according to the academic specialization variable:}

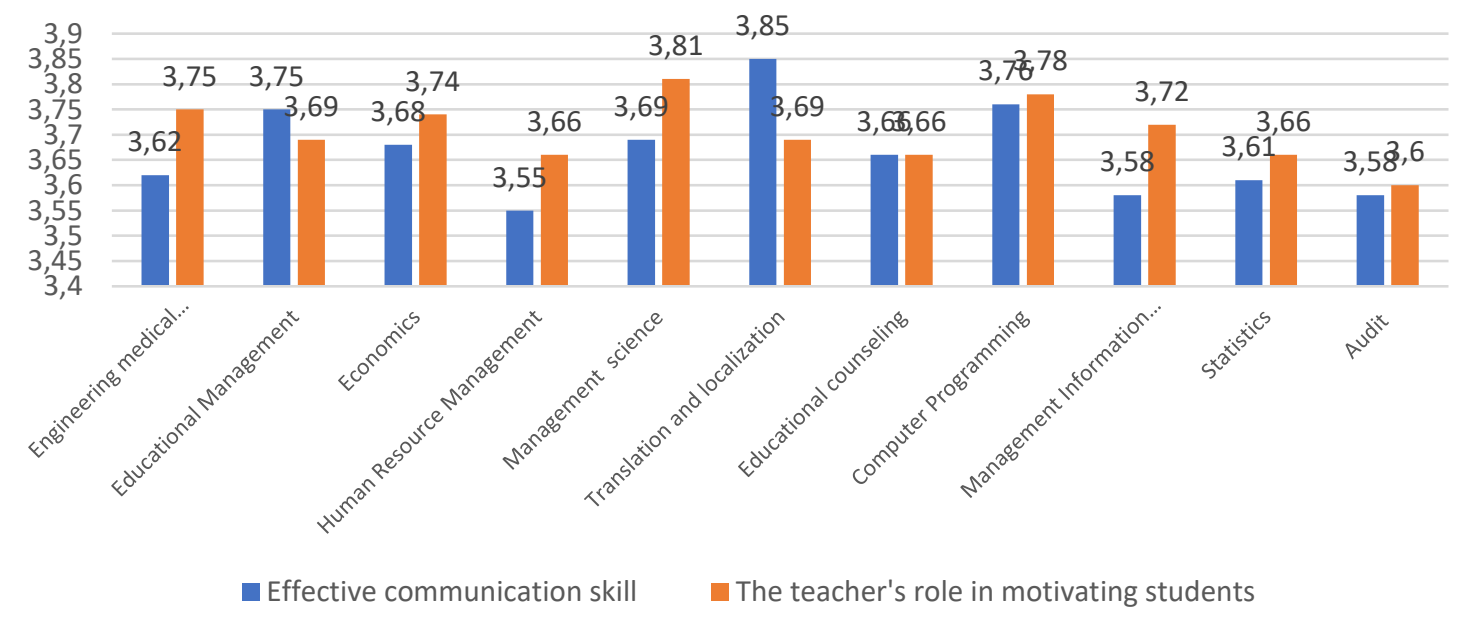

Graph No. (12) Comparing the arithmetic averages for each field according to the academic specialization variable 
Through the above graph, we have found that the highest arithmetic mean in possessing the skill of effective communication is set by teachers specialized in translation. While the lowest arithmetic mean for this skill is set by teachers specialized in human resources management. Meanwhile, the highest arithmetic mean for the student motivation skill is set by teachers specialized in administrative sciences major, and the lowest arithmetic mean for the skill is set by teachers specialized in auditing.

Comparing the arithmetic means for each field according to the teachers' university degree variable:

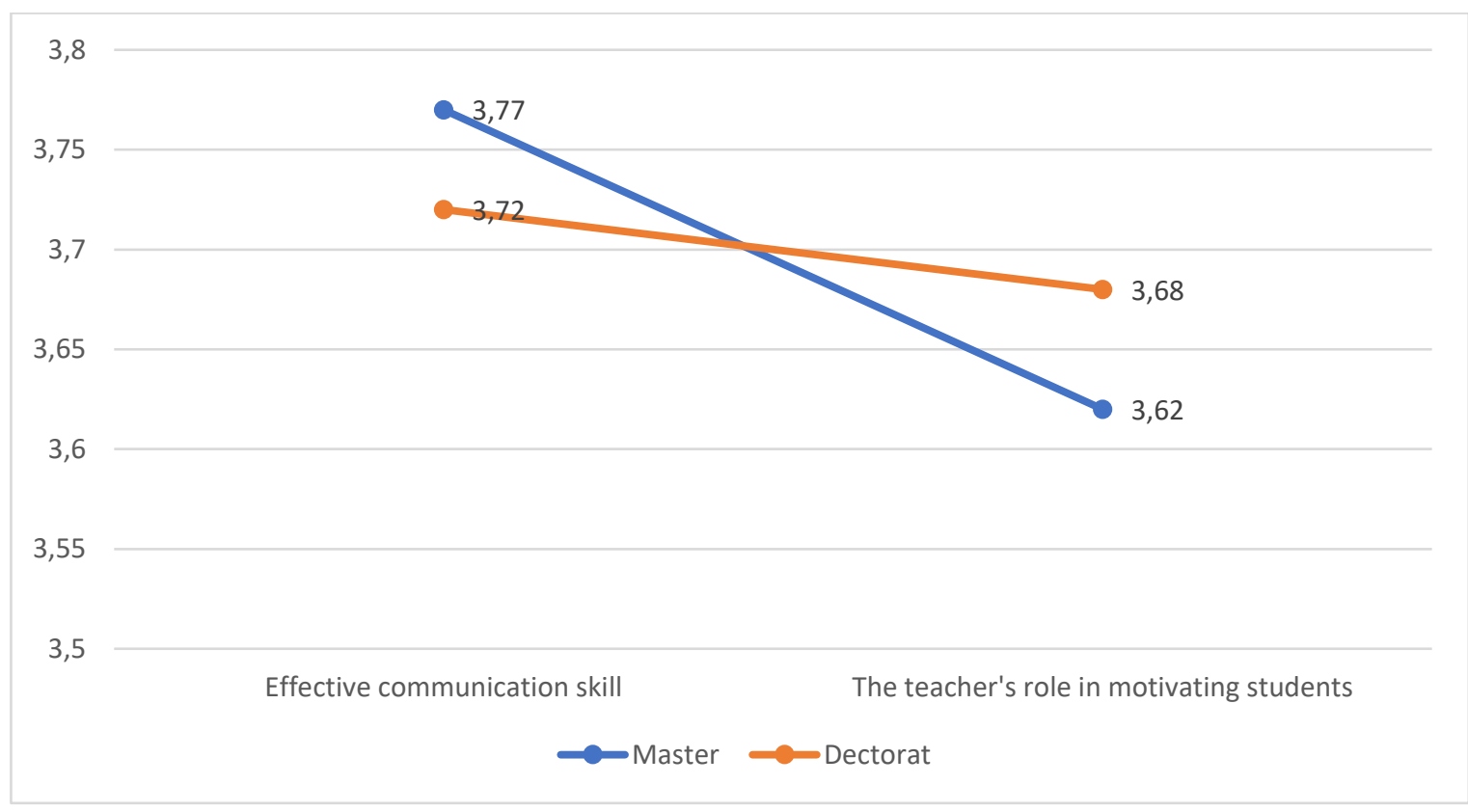

Graph No. (13) Comparing the arithmetic means for each field according to the teachers' university degree variable

Through the above graph and based on result of statistical analysis, we have found that the highest arithmetic mean for possessing the skill of motivation is set by teachers who have a master's degree (3.77), while the arithmetic mean of teachers who have a doctorate degree reached (3.72). Meanwhile, the highest rate of possessing the skill of effective communication was set by teachers with a doctorate degree (3.68). Accordingly, these results should not be final, and teachers, regardless of their academic degree, must strive to improve and develop their skills.

\section{Comparison of the arithmetic means for each field according to the variable of practical experience:}




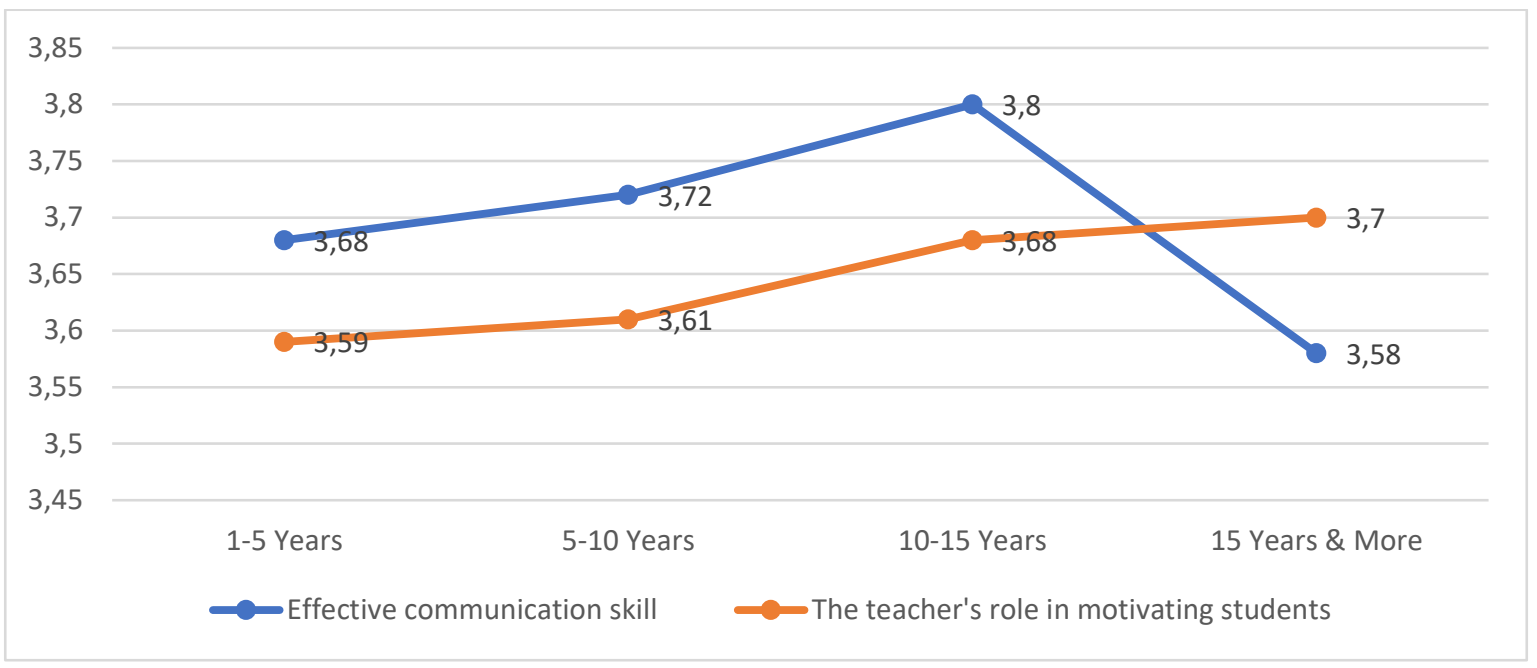

Graph No. (14) Comparison of the arithmetic means for each field according to the variable of practical experience

Through the above graph, we have found that the highest arithmetic mean for possessing the skill of effective communication (3.80) is set by teachers who have practical experience ranging between 10-15 years. While the lowest arithmetic means for the said skill (3.58) is set by teachers who have practical experience of more than 15 years. As for the students' motivation skill, the highest arithmetic mean (3.7) is set by teachers with practical experience of 15 years and above, while the lowest arithmetic mean (3.59) was set by teachers who have practical experience ranging between (1-5 years).

The results of the study reflect that university teachers in Lebanon, particularly in private universities, were prepared to handle the digital divide resulting from the urgent need for incorporating new methods of teaching. Most of the respondents indicated their readiness and familiarity with distance learning environment. As the results revealed, private universities invested early in training their staff and preparing them to employ digital technologies in their teaching. In the contrary, a study in Jordan (Alharbi, 2020) pointed out that universities in Jordan are not prepared enough to cope with the current crisis due to the absence of strategic planning and effective management. In Lebanon, it can be concluded that private universities were alert and ventured early in the adoption of online learning. Nevertheless, further studies should be conducted to investigate the students' perceptions about online learning.

Through a survey of teachers' opinions about the distance learning process, we found that there is a need for adding courses that contribute to the student's acquisition of the technological skills required for the distance learning process. Enrolling both teachers and students in training programs prior to the fall semester of the academic year 2020-2021 is also the best means to make the distance learning process successful. Likewise, those who are responsible for developing study programs should be aware of the need to include means that help students develop their self-learning skill in the study programs. Especially since we are in an era that requires us to keep up with many technological programs and use many digital means. 


\section{Conclusion and Suggestion}

The study examined the role of effective digital communication skills in the success of the distance learning process in the private universities in Lebanon. It also addressed the role of the teacher in motivating the students and acting as a facilitator to bridge the digital divide. The results of the study indicated a satisfactory level of preparedness among private university teachers in Lebanon. This can be attributed to the good educational management practices adopted by the private universities. It was evident in the teachers' answers to the questionnaire of this study that the teacher plays the main role in the success of the distance learning process by possessing the skill of digital literacy and by constantly working on exposing and familiarizing themselves with newly-emerging instructional technologies. After all, the effective use of instructional technology is the basis of online teaching/learning. It is also found out that the motivation skill is complementary and may emerge the most important skill in the process of distance learning. The distance learning process cannot be carried out without internet access, and without the necessary know-hows of using digital facilities to deliver knowledge to the student. It is recommended that educational institutions set up training programs and courses that aim to develop the necessary skills and improve the process of distance learning outcomes. This has been proven necessary since the present study illustrated that the distance learning process can success when teachers are digitally literate. The study showed that the older the teacher, the more difficult it is to deliver successful online teaching. The challenges posed are largely ascribed to the digital divide. Further research studies may focus more on this concept with empirical and experimental data.

\section{Conflict of Interest}

The authors of the article declare no conflict of interest.

\section{Funding}

This research study was not funded by any institution. The authors conducted the study at their own expenses.

\section{Availability of Data and Material}

The data that support the findings of this study are available from the corresponding author, upon reasonable request.

\section{References}

Alharbi, M. (2020). The economic effect of coronavirus (COVID-19) on higher education in jordan: An analytical survey. International Journal of Economics \& Business Administration (IJEBA), 8(2), 521-532.

Clark, J. T. (2020). Distance education. In Clinical Engineering Handbook (pp. 410-415). Academic Press. 
Colley, C. H. (1929). Social Organization: A Study the Larger Mind. Charles Scribner's Sons.

Dornyei, Z. (2007). Research methods in applied linguistics: Quantitative, qualitative, and mixed-methodologies (pp. 95-123). Oxford: Oxford University Press.

Elliott, R., \&Timulak, L. (2005). Descriptive and interpretive approaches to qualitative research. A handbook of research methods for clinical and health psychology, 1(7), 147-159.

Fisher, D. A., Brush, A. J. B., Jacobs, A. W., Smith, M. A., \&Neustaedter, C. G. (2010). U.S. Patent No. 7,720,916. Washington, DC: U.S. Patent and Trademark Office.

Goforth, H. (2015). Using and Interpreting Cronbach's Alpha. University of Virginia Library.

Hege, I., Tolks, D., Kuhn, S., \&Shiozawa, T. (2020). Digital skills in healthcare DigitaleKompetenzenimGesundheitswesen-eineStandortbestimmung. GMS Journal for Medical Education, 37(6).

Hodges, C., Moore, S., Lockee, B., Trust, T., \& Bond, A. (2020). The difference between emergency remote teaching and distance learning. Educause Review, 27.

Ilmiyah, S., \&Setiawan, A. R. (2020). Students' Worksheet for Distance Learning Based on Scientific Literacy in the Topic Coronavirus Disease 2019 (COVID-19).

Lane, D. M., Scott, D., Hebl, M., Guerra, R., Osherson, D., \& Zimmer, H. (2017). An Introduction to Statistics. Rice University.

Lemonnier, P. (2016). Mundane objects: Materiality and non-verbal communication. Routledge.

Long, J., Liu, T. Q., Liao, Y. H., Qi, C., He, H. Y., Chen, S. B., \&Billieux, J. (2016). Prevalence and correlates of problematic smartphone use in a large random sample of Chinese undergraduates. BMC psychiatry, 16(1), 408.

Murillo-Zamorano, L. R., Sánchez, J. Á. L., \& Godoy-Caballero, A. L. (2019). How the flipped classroom affects knowledge, skills, and engagement in higher education: Effects on students' satisfaction. Computers \& Education, 141, 103608.

Mukhtar, K., Javed, K., Arooj, M., \& Sethi, A. (2020). Advantages, Limitations and Recommendations for online learning during COVID-19 pandemic era. Pakistan journal of medical sciences, 36(COVID19-S4), S27.

Orellana, M. L., Darder, A., Pérez, A., \& Salinas, J. (2020). Improving doctoral success by matching $\mathrm{PhD}$ students with supervisors. International Journal of Doctoral Studies (IJDS), 2016, vol. 11, p. 87-103.

Simonson, M., Zvacek, S. M., \&Smaldino, S. (2019). Teaching and Learning at a Distance: Foundations of Distance Education 7th Edition. IAP.

Stanek, S., Drosio, S., \&Namyslo, J. (2014, May). Experiences with Building Modern Communication-Driven Decision Support. In DSS (pp. 483-494).

Staveteig, S. (2016). Understanding unmet need in Ghana: Results from a follow-up study to the 2014 Ghana Demographic and Health Survey. ICF International.

Subotzky, G., \&Prinsloo, P. (2011). Turning the tide: A socio-critical model and framework for improving student success in open distance learning at the University of South Africa. Distance Education, 32(2), 177-193.

Vogt, W. P., \& Johnson, B. (2011). Dictionary of statistics \& methodology: A nontechnical guide for the social sciences. Sage. 